\title{
Sustainable Development of Iranian Historical Cities with Focus on Cultural, Historical and Architectural Identities
}

\author{
Mazdak Irani, PhD Candidate
}

University of Sydney, Sydney, Australia Email: mazdakirani@mail.com

Doi:10.5901/mjss.2014.v5n7p647

\begin{abstract}
"Sustainable development" refers to some solutions for non-appropriate patterns in body, spatial, social, cultural and economic in order to prevent all levels and fields that lead to negative shifts. It requires considering sustainable architecture and its formation in architectural designs for in-depth knowledge of sustainable purposes. Sustainable architecture is a process which can be repeated. The conception of sustainable is related to evaluate the value of a method. This method will be faced to current protective needs through a repetitive and durable behavior. Therefore, here this process will be consideredas the same of final product.Certaintly, sustainable architecture is able to recognize that the final product may become exhausted or replaced as require. Therevival phenomenon of urban historical and cultural basis as the concept of revitalization is very important issue considered by experts and officials based on urban economic. Some discussions have been done for this phenomenon but there is not enough study and evaluation yet. Historical and cultural basis is known as a path which involves various buildings and relatively numerous for public application with architectural identity in internal and external spaces. It is as a subject forrecognitive researches. In this study tried to consider the process of sustainable development based on historicalcultural basis.
\end{abstract}

Keywords: process, revitalization, sustainable development, historical cities, recognitive, heritage protection, cultural and historical values, identity.

\section{Introduction}

In Iran architectural principles have been used based on different experienced for long time indicated that repeatable features and values of vernacular architecture are under-developing for sustainable architecture formation. Urban historical contexts are appropriate sample. These contexts indicate traditional Iranian architecture and focus on following:

- Look at nature and its sacred association

- Design and human design processes

- Building reliability

With the importance of urban spacesome features of historical and cultural effectswill be studied by the view of urban planning and designing. First, each building and urban space constructed to provide human various and tangible needs, so body identity and architectural values and one-sided emphasize on old buildings and monuments individually and also ignoring their relationships with lifestyle, public spaces and people culture that are settled near them can lead to deal with urban sustainable development and spacial planning.

Therefore, consider to historical and architectural values as a part of public values of urban life in direct relation with city and citizens is essential. Hence,preservation of historical and cultural monuments is not good reason to seperate them from people, but their optimal utilization should be possible. Second, however, historical buildings and spaces will be worthy after years, daily life for people in a city will be valuable and in turn, it requires for retention and spatial visualization. According to urban sustainable development, in addition topreservation and revival historic and traditional values, creation of new urban memorial and signs can lead to body and spatial identity for new values and direct and creative relationship between past and future.

Third, traditional and historical monuments and buildings are special parts of public values in a city. Hence, retention and enhancing just one aspect of architectural and body values is not enough to develop urban spaces, and it needs to consider historical and cultural values for urban public life and in relevance to other values of public life.Fourth, urban historical and cultural values are not only related to the monuments of government and central area of city, but each corner and region of the city has its own history and values that in turn can help to local identity and community as well as urban diversity and liveliness generally. It must be noted that there is no proper identification for historical contex 
and life within it. This issue causes some problems in new urbanization, and modernization can lead to serious damage to historical contexts of its social construction.Some researches indicate that people who live in a area have more close concerns and attachments together with more sympathy and attempt to preserve and revive it. Fifth, cultural values in current world are main resource to develop economical values that lead to increase postmodern and lifestyle shifts and more interest in cultural spaces and use more cultural goods and search for beauty and historical-cultural identity in personal and social lifestyle. In this article, the relationship between cultural, historical and Islamic values of historical cities of Iran with spatial-body development and extend it to sustainable development aspects will be studied.

\section{Model of Sustainable Development}

Sustainable development is a controversial concept with more widespread concepts. At an abstract and subjective level,there is a significant relationship between stability and conservation or improvement of natural integrated systems in relevance to our world lifestyle generally.Because of human authorities and activities that affected on world significantly, human population is main core of these systems and their stabilities.Natural limitations and humans choices in relevance to economic, environment, culture (include values and policies) and population is important to determine earth capacity for humans support. Therefore, the capacity of earth to support human is dynamic, variable and uncertain (Cohen, 1995).

"Sustainability in a dynamic system such as human society is related to stability over time. So, this concept is not measurable easily because it is a non-stable quality not a stable point" (Moldan\&Bilharz, 2003; 84). Sustainable urban can include various models in relevance to region history, culture, economic basis, climate, environment and policies.Sustainability basically should emphasis on human purposes as a main core of each approach.The issue of urban performance is about the quality of human settlements. Following four characteristics are explained to show development is sustainable.

Efficiency: in fact it refers to relationship between natural systems and economical-social systems to guarantee food production and other goods for people and is known as dynamic equation and is harmless for the system. Efficiency estimates the capacity of society use or shift the natural systems for food production and goods with optimal output (Kiyani, 2008;5).

Justic: means the capacity of society in equitable distribution of opportunities and challenges derived from natural systems use and shift like distribution something that result from development process. It is also used about distribution of wealth among people.

Flexibility: is the capacity of society in response to imposed or natural pressures or sudden impact. Flexibility means system capability to improve or preserve of productivity levels in short- term or long-term irregularities.

Stability: means the capacity of society to use or shift the natural systems process without extreme transformation (Moldan\&Bilharz, 2003;387).

Therefore, a model of historical urban sustainable development of Iran should adjustable and adaptable during social and economic shifts and cultural values of a society. However, population is known as main component in sustainability, it requires to study about the impact of population on economical,social and environmental factors which converts city into an integrated system (Figure 1). 


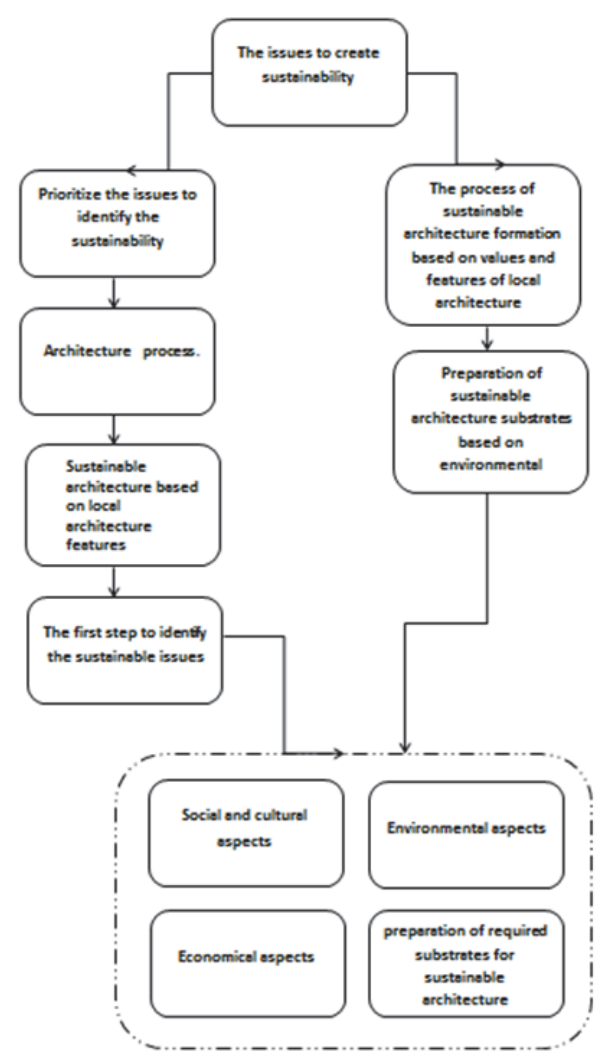

Fig.1: Model of sustainable architectural development as an outline

\subsection{Effective factors in the formation of urban spaces}

Following factors are related to some infrastructures for urban spaces formation in Iran (Fig.2):

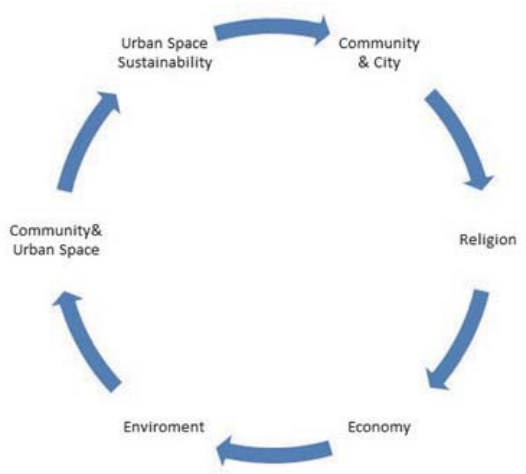

Fig.2: main factors in Iran historical urban development

Religion: human lifestyle and their activities affected by world viewpoint and have relationship with each structure and human behavior directly. Islamic urban spaces are formed through religious values. So, many cities in Iran in addition to climate and natural environment have spatial system. In Iran, cities also are affected by culture and Islamic 
beliefs.Economic factor: there is a significant relationship between economic factors and the formation of urban spaces and types of economic methods, also different spaces are formed by these factors (Shahabi,number 72,137).Climateenvironmental factor: habitat and the city are formed by this factor. Main principle to form urban spaces is relationship between environmental status and constructed spaces of cities (Habibi, 2006, 40-48). Homogenous spaces are known as traditional urban spaces in Iran (Tavassoli, 2000,36). There is a significant relationship between above three factors. Environmental factors and religious values are two important factors for Islamic cities. Spatial-physical factor has significant impact on Islamic culture. Society and individuals are also affected by mentioned factors. Urban water supply network additionally is more significant factor to form cities.

\section{The Model for Identity Preservation in Sustainable Development of Historic Cities in Iran}

According to a beauty interpretation, the nature of identity is "I am because of that and I'm alive". This nature is derived from both individual and society in a historical context.As some factors such as language, clothes, methods of production, regulations of governance and many other factors are parts of our national components and identity elements and cultural affiliations, many factors such as science and technology, skills, thoughts and experiences are obtained by others will be part of our identity as the mystery of our survival (Farasatkhah, 72).

Our country is one of the richest countries in terms of available heritage and cultural achievements, for examplespecific urbanism and architecture that known worldwide. With respect to this issue that how would our life be today and how to think future and How do we benefit from our past? , so it is very important to construct cities and produce architectural components (Barzgar, 2004; p.195).hence, we need to review and developtheir past and current identities (Figure 3).

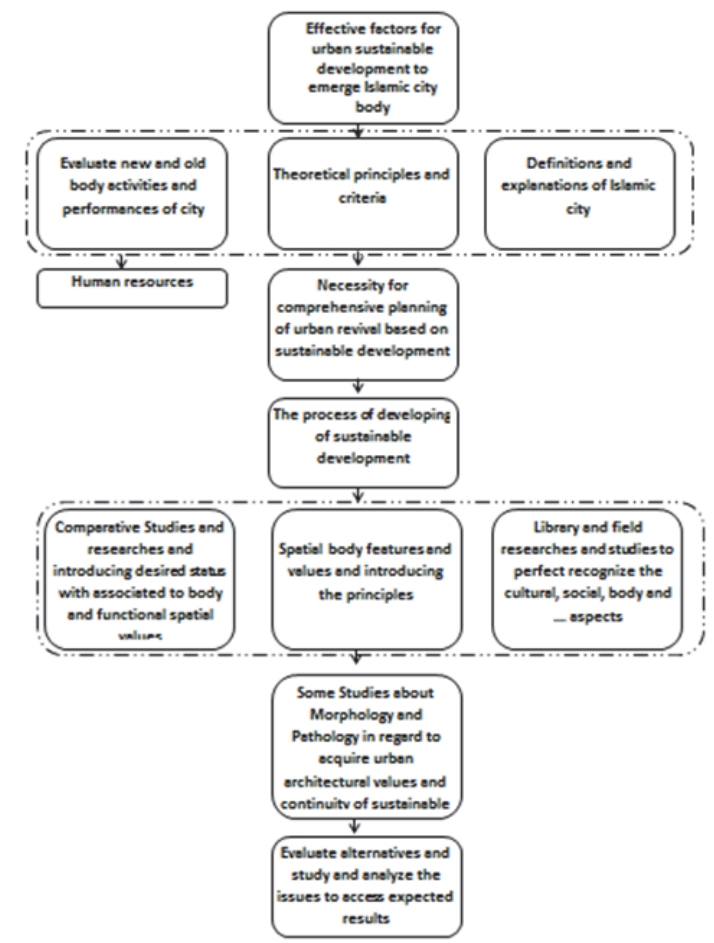

Fig. 3: Comprehensive plan to revive the identity of sustainable development

\subsection{Cultural identity in historic urban sustainable development of Iran}

Sustainable development focus on consumerism lifestyle and the process of making decision that are only based oneconomic efficiency and also evaluate behavior infrastructures more than economical and environmental requirements. In fact, sustainable development as a comprehensive and innovative process need to have stable development (Newman 
and Kenworthy,1999). The fact that sustainable development is relied on variable values and ideas of local and global communities makes it more complex (Williams, 2003).

Culture is very important issue in social, economical and environmental models, but there has been no appropriate understanding and knowledge about that yet.For example, Hilguard Kurt in the aesthetics of sustainability refers to lack of cultural considerations in sustainable development. He also focuses on inattention the cultural and aesthetic dimensions of sustainability in natural and social sciences. Here, the comparison between its features and principles with other approaches of urban sustainable development will be studied before its concepts. The results from different resources in this field are shown as the figure.

According to different aspects of sustainable development, specific focuse and objectives of each aspects of sustainable development will be evaluated, including; environmental aspect focuses on environmental resources and maintaining them which lead to environmental sustainability; economical aspect focuses on available information and facilities in order to achieve justice and potential competitiveness; also social justice and equality of rights are essential to achieve justice; and finally, cultural sustainability focuses on cultural identity and its purpose is access to diversity and differentiation or cultural diversity in other word. First, in order to know cultural diversity requires to knowing about culture.According to Edward Barnet Taylor(1871), " totally, culture is a complex issue involved knowledge, art, law, morality and other human ability and habit acquired from society" (Ashoori,2003). So, the purpose of cultural diversity is "different methods of culture from prople and societies that many various methods caused to create, produce, distribute, and value it" (UNSCO,2001;UNSCO, 2005). This definition can improve the great, wide and various identity of culture, it now focuses on multi-dimension devices and different processes that help to convert culture. Recently, due to the importance of this dimension in sustainability, culture became as a part of social aspects of sustainability or part of social source and there were no appropriate studies about that.For example, according to Mattio Pike (2003), as some researches done about social sources, there are less considered about art sources such as music and like that, and other values are more important for people generally. Some of these problems derived from cultural attentions (Assefa\&Frostell, 2007, 64-65). Mark Roseland (2005) explained that sustainable society should be able to keep and produce own resources and face to future problems. For example, many of sciences try to show the relation between the concept of social source and the concept of social sustainability, as in the form of networks and encouraging public accommodation or information, perceptions and patterns of interaction and networking that a group of people show by their activities (Roseland, 2005; Coleman1988; Putnam, Leonardi and Navetti, 1993). Location in local communities have main role because of its role to encourage people and civilizations to make decision about their future environment and resources (Duxbure\&Gillete, 2007). In local community, cultural development is known as a collective process and often include some innovations are provided in large scale. It also causes many changes for people lifestyle and involves development and long-term benefits for society (Mills \& Brown, 2004).

In fact, cultural development of a society is part of growing framework of sustainability and societies have opportunity to present their stories and also complete their innovative skills and actively participate to develop culture ( $\mathrm{O}^{\prime}$ Hala, 2002). Using some devices such as art and culture to develop society culture, it is possible to provide appropriate sustainability models into society. There is no single model for cultural development as is for other sustainable development models; but it is important for all existence models to change the relation between artists and society to "partnership" relation instead of "technical and general" relation(Mills and Brown, 2004).Therefore, there is significant interaction between culture (culture values) and architecture/urbanization. Many reasons indicated that the impact of architecture and urbanization on culture is very complex and substantial. It should note that culture in a society has direct impact first on humans' lifestyle and their activities and second on create spaces. Many researchers and even those who try to change nations'life spaces and their architecture/urbanization and environment, first try to change a community culture, then they focus on architecture/urbanization because of its significant impact on human lifestyle, environment, communications and culture. Currently, because of non-appropriate architectural and urbanization principels and theories as well as incorrect issues and develop some specific architectural methods, the impact of architecture and urbanization on culture is important significantly. So, following indicate that environment (urban architecture) have identity:

Identity of artificial environmentindicate society values

- Identity of artificial environment indicate some values that society try to aquire them and develop with

- Features of artificial environment indicate such identity that society try to know with that

- Features of artificial environment indicate some societies that create environments and live

- Features of artificial environment indicate the identity that somebodies (such as city planners, designers and managers) try to provide for society. (Figure 4) 


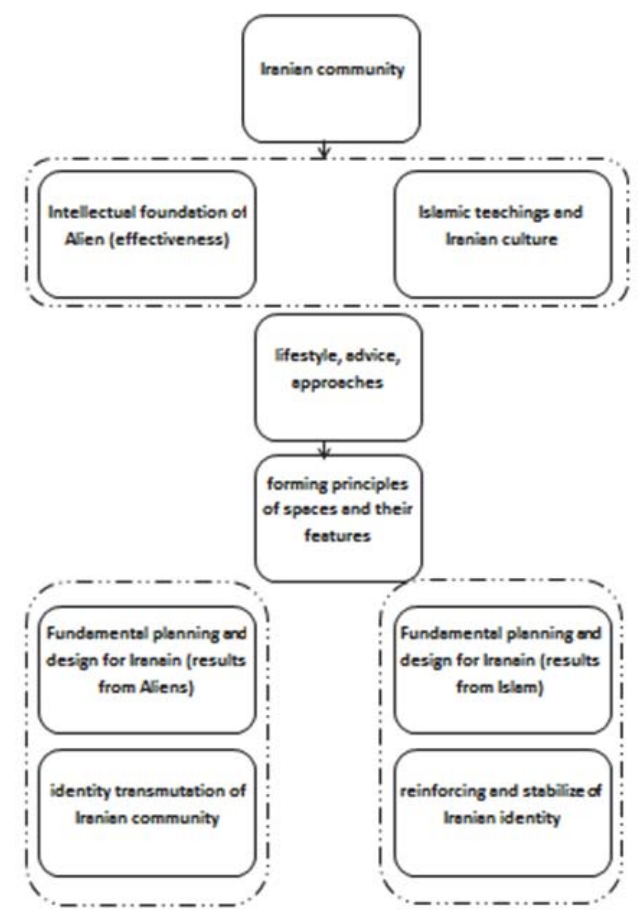

Fig. 4: The stabilization plan of Iranian culture in historical cities

\subsection{Traditional identity in sustainable development of Iranian historical cities}

Identity of Iranian historic cities has been clear based on its specific characteristics and was different from non-Iranian cities such as the cities of non-Islamic countries specially, and this identity and its differences have been presented first by aliens.Body identity, functional identity, historical identity, cultural identity, environmental identity, natural identity, religious identity, human identity, acquired identity, national identity and social identity are significant effects of the Iranian historical urban identity (Naghizadeh; 2008, 121).

It must be noted that historic- Islamic cities of Iran have biological order and spatial organizing of buildings and passages never faced to disorder problems. Infrastructure, geology and order of a city gradually will develop (Afshar, 1996; 4-53). One aspect of Islamic cities is complex and tangled context cause for more proximity and social solidarity that people can be more closely together. Historic cities of Iran have been constructed by a organic order in addition to disorder context.Also walls have been important role to cover the main core of cities in Iran. A complex but organic order context is used for passage network that cause to establish defence factors, ways, bazaars, irrigation canals, religion and other cases.For example, around Iranian traditional cities, a special rational system in traffic network included main street and subsidiary street has been suggested by Man and Friedman. According to them, land possessions and topography are components of geology and important in rational system. They studied about effective factors on orientation of streets and buildings in city Kerman (1971-1975). They found that first cultural concepts of Iranian settlements were based on topography and water supply. Bonine (1979) as a geographers used this method later and a spatial approach proposed by him. In 1979, his article as "Genetically morphology in Iranian cities" presented that regardless of religion, spatial models and city affected by other factors. In Iran, physical contexts of traditional cities are not just related to topography and water. In order to form streets some other factors such as climate, wind, business, and defensecan be effective (Kheirabadi, 1997;17,50).It must note that there are some different factors such as religion, natural environment and economy are effective in morphology of Iranian traditional cities not just one (Kheirabadi, 1997;114). Also, such these mentioned factors have been obtained at least during thousands years that led to develop and form Iranian traditional cities gradually. 


\subsection{Islamic identity in sustainable development of Iranian historical cities}

One of the main purposes to provide human needs of today's society is recognition the methods of identification and Iranian and Islamic revival. This purpose will be acquired through use of symbols and signs, use of national and local arts, spatial organization and urban elements, rational relationship with past and other appropriate cases.

\subsubsection{Theories of Islamic cities formation}

The issue of initial cities and the impact of agricultural economy on them was considered by many eastern and western historians. Agriculture theory was central theory to form cities and therefore with increasing demand and the need for products, markets were formed (Tavassolian, 2000, 34-36). According to some researchers, location and water are main steps to form cities (Etezadi, 1989,78). Some cities such as Rabat, capital of Marrakesh that had military usages were formed by strongholds. In addition, tomb of religious people such as Karbala, Meshhad and Quom were located around the cities (Ashraf, 1963, 8-50). The purposes to form cities in Islamic countries are different from each other. Some factors such as urban infrastructures and use natural factors such as access to water and form agricultural centers, human factors such as political, economic, cultural, religious and social factors are important to form cities. Of course, religious beliefs can be mentioned as cultural factor to form cities, according to AmusRapaport's theory $(1987,19)$.

\subsubsection{Identity of Islamic impacts on Iranian historical cities}

According to the concept of identity, the impact of human status such as environment, urban and architecture will be presented. If patterns are formed against God and is propagator of devil lifestyle, if its body and space is formed against values and is harmful for God values and principels, if this environment lead to non-value for society and if the body of environment cause to the way of thinking and living against God values, it must note that devil's identity have impact on city identity, and versus if the pattern is human pattern and based on God values and propagator of human lifestyle and cause the society guiadance to the way of thinking and living in the God values, it must note that God identity have impact on city identity (Naghizadeh; 315). Effects of God identity, devil identity and their results is shown as figure 5.

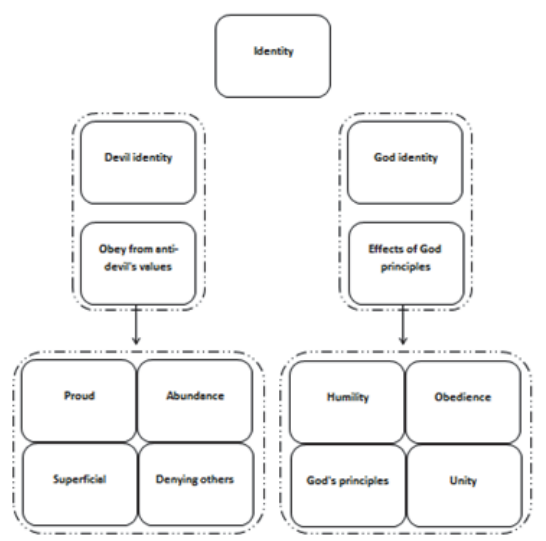

Fig. 5: Effects and manifestations as two main factors of human identity in Islamic identity

Among authors special Muslims, there is relationship between originality and truth with God's aesthetic and spiritual. Appearance aesthetic is called as ornament.Ghazali believed that the world of Alavi is beauty and good and the principel of beauty and good is proportion and everything is proportionate. It is an effect of beauty of the world, everything is beauty, good and proportion in this world as "beauty of creator of love". All results are beauty and good of that world and love is the result of relation with beauty, and love should guide human to perfection, and if it didn't happen love neither is love nor beauty is beauty, but both are virtual andillusions of love and beauty. There is significant relationship between beauty and love. It means that different steps of beauty assume with some issues such as art, good,balance, proportion, enjoy and etc associated and sometimes synonymous, but highest level of beauty is associated with love (Figure 6\&7). 
Fig. 6: Reviewed Islamic identity in contemporaryarchitecture

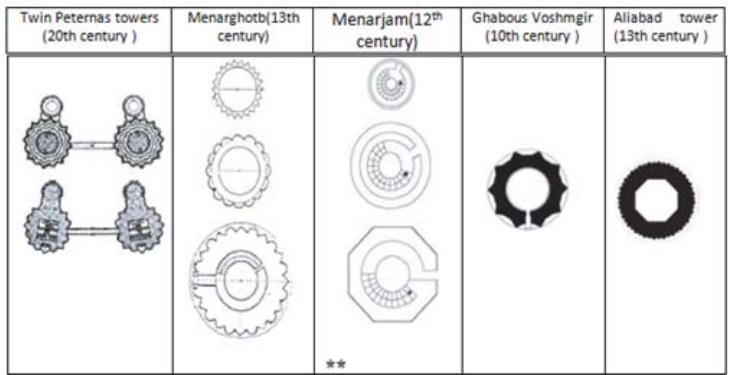

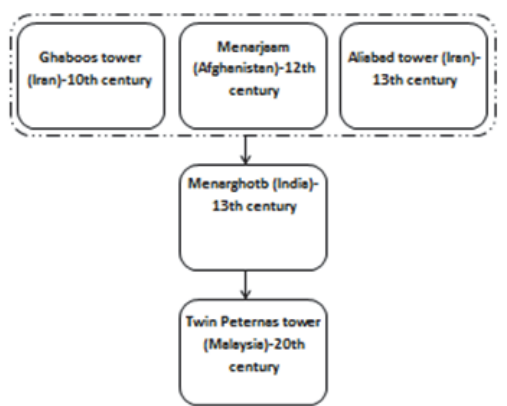

Fig. 7: A sample of effective process of Islamic identity

\section{Conclusion}

The revival of urban culture and history is very important and is considered by professionals and experts for urban economical ability. There are not enough conditions to evaluate and study about that yet. Executive laws have been established to keep and repair historical buildings in our country are focused on single buildings or units and sets of architecture-urban and also valuable interurbanand suburban units (even near or within villages) such as Massoleh and Abiyaneh in Iran. But, there are some specific problems include requiring to large funds and lack of urban officials preparation and unclear required fields of recognition moral values in the context of historic urban both from residents and owners. Historic-cultural aspect is a path involved various buildings that had public usages (or still have) are different from architectural identity and characteristic in internal and external spaces. It is a title for recognition researches (Falamaki, 2005;p.185).

\section{References}

Abel, Chris, 2000. Architecture and identity (responses to cultural and technological changes), Architectural press.

Amos (1990) "The Meaning of the Built Environment" Revised Tucson, University of Arizona Press.

Alexander, C.; S. Ishakawa and M.Silverstein (1977) "A Pattern Language - Towns, Buildings, Construction"NewYork, Oxford University Press.

Ashworth, G. J. (1998) The Conserved European City as Cultural Symbol: the Meaning of the Text',In B. Graham (Ed.), Modern Europe: Place, Culture, identity. London.

Assefa, G. \&Frostell, B. (2007) "Social Sustainability and Social Acceptance in TechnologyAssessment: A Case Study of Energy Technologies", Technology, in Society, No.29, pp. 63-78.

Beatley, Timothy \& Manning, Kristy (1997) The Ecology of Place: Planning for Environment,Economy.

Barzgar, Mohammadreza; 2009, recognition of urban identity, Articles of the Conference of Urban Affairs in Iran; first Vol.; urban construction, Shiraz, Shiraz Uni.

Blankenship, Sherry (2005) "Outside the Center: Defining Who We Are", Design Issues, www.mitpressjournals.org/doi/pdf $110.1162 / 0747936053103084$.

Borrup, Tom (2004) "Creative Organizations: Putting Culture to Work in Community Development",Community Arts Network, URL: http://www.communityarts.net/readingroom/archivefiles/2004/01/creative_organi.php.

Coleman, J.S (1988) "Social Capital in the Creation of Human Capital", American Journal ofSociology, No. 94. 
Colantonio, Andrea (May 2009) Social Sustainability: Linking Research to Policy and Practice,Sustainable Development - a Challenge for European Research, Brussels.

Cohen, Barney, . "Urbanization in developing countries: Current trends, future projections,and key challenges for sustainability", Technology in Society xx: 2005, (1-18).

Cohen, J ."Population growth and earth's human carrying capacity". Science 269: 1995,(341-347).

Darlow, Alison (1996) Cultural Policy and Urban Sustainability: Making a Missing Link? PlanningLtd, London.

Declaration of Cultural Human Rights (1984), "Re-issued as the last act of the Alliance for Cultural Democracy", URL: http://www.communityarts.net/readingroom/archivefiles/2004/08/declaration_of.php.

Duxbury, Nancy \& Gillette, Eileen (2007) Culture as a Key Dimension of Sustainability, ExploringConcepts, Themes, and Models, Creative City Network of Canada.

Duxbury, Nancy, Derek Simons, and Katie Warfield (2006) Local Policies and Expressions ofCultural Diversity, Creative City Network of Canada, Vancouver, British Columbia, Canada.

Falamaki, Mohammad Mansour; 2005, The privacy of Iranian cultural resources, Faza publishing Co. first edition

Falamaki, Mohammad Mansour; 2004, renewal the historic-cities and buildings, Tehran Uni. Publishing Co., $5^{\text {th }}$ edition.

Farrasatkhah, Maghsoud, 2006; Contrasting imported architectural styles with the values and principles of Islamic architecture, Articles of the third seminar on housing development in Iran, Tehran, Departmentof Housing andUrban Development.

Fraser, Fil (1994) The Participation of Aboriginal and other Cultural Minorities in Cultural Development, Canadian Journal of Communication.

Grazian, David (2003) Blue Chicago: The Search for Authenticity in Urban Blues Clubs, Chicago:University of Chicago Press.

Hitchens, dreck; 2003,Application of systematic thought, translated by Rashid Aslani, second edition, high institute of Management and Planning education and research, Tehran.

Hawkes, J. (2001) The Fourth Pillar of Sustainability, Australia: Cultural Development Network,www.theHumanities.com.

Henderson, V.; Kuncoro, A. and Turner, M, ."Industrial development in cities", Journal ofPolitical Economy 103: 1995, (1067-1090).

Jacobs, Jane (1969) "The Death and Life of Great American Cities" New York, Vintage Rapoport.

Jong-jinkim,Sustainable Architecture module: Qualities. Use and Examples sustainabil building materials.

Kiyani, Mostafa; 2004, sustainable development and reconstruction of Bam, Aabadi, Centre for architectural and urbanization researches and studies, 14yh years, NO. 42 (NO.17th as new course)

Kurt GrotterYurk; 2006, AestheticsinArchitecture, translated by Naghizadeh, Mohammad, Abdolrezahomayoon. Shahidbeheshti Uni. Publishing Co.4th edition

L. Moss, M.; M. Kaufman, S. and M. Townsend, A."The relationship of sustainability totelecommunications", Technology in Society 28 : 2006, (235-244).

Ley, David, \&Germain, Annick (2000) Immigration and the Changing Social Geography of Canadian Cities, Vancouver: Department of Geography, University of British Columbia.

Ledwith, Margaret (2005) Community Development: A Critical Approach, Bristol, UK: Policy Press.

Moldan, Bedrich and Bilharz, Soozan; 2002, Indicators ofsustainable development, translated by NeshatHadadTehrani and NaserMoharamnejad, Environmental Protection Agency publishing Co., Tehran.

Matthews, John \& Herbert, David, (Eds.) (2004) Unifying Geography: Common Heritage, SharedFuture? Oxfordshire, UK: Routledge.

Mills, Deborah \& Brown, Paul (2004) Art and Wellbeing, Sydney, Australia: Australia Council forthe Arts.

Mitlan, Diana \&Satterthwaite, David (1994) Cities and Sustainable Development: Background Paperfor Global Forum '94, London: International Institute for Environment and Development.

Newman, Peter \&Kenworthy, Jeffrey (1999) Sustainability and Cities: Overcoming AutomobileDdependence, Washington, DC: Island Press.

Naghizadeh, Mohammad; 2008, Islamic city and atchitecture, Mani publishing Co. first edition

Naghizadeh, Mohammad; 2006, the principles of ReligiousArt in Islamic culture, second volume, first edition, Rahian publishing Co.

Naghizadeh, Mohammad; 2006, 2003, environmental planning for land development (guide for sustainable local planning and designing), translated by Dr. SyadHosseinBahreini and KeyvanKarimi, first edition, Tehran Uni. Publishing Co.

Naghizadeh, Mohammad 2006,2002, social resources and urban management, Journal of urban management, Ministry of the Interior, Municipalities of the country, second years, NO. 7, Autumn.

Naghizadeh, Mohammad 2006, urban sustainable development, Interpretationandanalysis ofglobalperspectives, Faculty of Urbanization and architecture , ShahidBeheshtiUni, $11^{\text {th }}$ years, NO.33, Autumn and Winter.

O'Hala, Scott (2002) Hand ON! Practices and Projects, Community Cultural Development Board,NSW, Australia: Australia Council for the Arts.

Pike, Matthew (2003) Can Do Citizens, London, UK: Social Enterprise Services \&Scarman Trust.

Putnam, R., Leonardi, R., \&Nanetti, R. (1993) Making Democracy Work: Civic Traditions in Modernltaly, Princeton, NJ: Princeton University Press.

Roseland, M. (2005) Towards Sustainable Communities: Resources for Citizens and their Governments, Island: New Society Publishers.

Rapaport,a, (1987),Cultural origin of complex biological,publication: IUST.

Saeedirezvani,A, (1987)Islamic vision and geographical landscape, Journal of Geographical Research, 6.

Shahabi,M,R,Principles and theoretical framework Moqufe effect in the formation of urban spaces, Journal of Geographical Research, number72, (135).

W.G. Newman, Peter. "Sustainability and cities: extending the metabolism model",Landscape and Urban Planning 44: 1999, (219-226). 